\title{
Lahares secundarios en el volcán Popocatépetl: El lahar Nexpayantla del 4 de febrero, 2010
}

\section{Gabriela Zaragoza' ${ }^{1}$, Lizeth Caballero-García ${ }^{2,}$, Lucia Capra $^{3}$ y Amiel Nieto-Torres ${ }^{1}$}

\author{
${ }^{1}$ Posgrado en Ciencias de la Tierra, Universidad Nacional Autónoma de México, Unidad de Posgrado, \\ edificio D, primer piso, Cd. Universitaria, Coyoacán, Ciudad de México, México. \\ ${ }^{2}$ Facultad de Ciencias, Universidad Nacional Autónoma de México, \\ Av. Universidad 3000, Circuito Exterior S/N, Coyoacán, C.P. 04510, Ciudad Universitaria, Ciudad de México, México \\ ${ }^{3}$ Centro de Geociencias, Universidad Nacional Autónoma de México, \\ Blvd. Juriquilla No. 3001, Querétaro, Qro., 76230, México. \\ *lcaballero@ciencias.unam.mx
}

\section{RESUMEN}

Los lahares secundarios representan una de las mayores amenazas en volcanes activos o en estado de quietud, por lo tanto, es importante estimar la frecuencia, distribución y los mecanismos disparadores en diferentes volcanes para establecer escenarios de peligro.

En este trabajo se analizó el lahar ocurrido el día 4 de febrero del 2010, en la barranca Nexpayantla, ubicada en el sector NW del volcán Popocatépetl. Para ello, se realizó un estudio geomorfológico y textural del depósito, así como de la precipitación y de imágenes de satélite tipo ASTER para delimitar el área de inundación y el mecanismo disparador. Los datos mostraron que este evento se generó por una precipitación de $100 \mathrm{~mm}$ /día e inició como una corriente fluvial, que se transformó en un flujo de escombros y finalizó como una corriente diluida. Su transformación, de corriente fluvial a flujo de escombros, se debió a la incorporación de sedimentos por erosión laminar y procesos de remoción en masa que ocurrieron en la barranca, asociados al mismo evento de precipitación. En contraste, su dilución a una corriente fluvial fue por la rápida sedimentación relacionada con cambios en la geometría del cauce, el alto contenido de troncos de árboles y el bajo contenido de material fino. La reproducción del evento mediante simulaciones numéricas permitió calcular que su profundidad pudo alcanzar $1.7 \mathrm{~m}$. Al comparar la distribución del depósito en campo y del lahar en las imágenes de satélite, se observó que el depósito representa sólo el 68 $\%$ del área total de inundación del evento. Asimismo, el análisis de la lluvia indicó que una precipitación de igual magnitud a la que disparó el lahar Nexpayantla, tiene un periodo de retorno de 27 años. Finalmente, trabajos enfocados en la caracterización de lahares secundarios en el volcán Popocatépetl permitirán establecer escenarios que incluyan casos como el aquí estudiado.

Palabras clave: Lahares secundarios; peligro; Popocatépetl; precipitación; erosión; procesos de remoción en masa.

\author{
ABSTRACT \\ Secondary lahars represent one of the major threats at active or qui- \\ escent volcanoes. Therefore, it is important to stablish their frequency, \\ distribution, and triggering mechanism to define hazard-scenarios.
}

In this work, an analysis of a lahar, that occurred on February $4^{\text {th }}$, 2010 in the Nexpayantla ravine, on northwestern sector of Popocatépetl volcano is presented. A geomorphological and textural analysis coupled with rain data and satellite imagery were used to determine its origin and to delineate inundation areas. This lahar was triggered by a 100 $\mathrm{mm} /$ day precipitation and initiated as a stream flow, that transformed into a debris flow, and ended as a stream flow. The transformation from streamflow to debris flow was due to sediment entrainment by laminar erosion and mass wasting processes. In contrast, its subsequent dilution was favored by changes in channel geometry, the high wood content, and the lack of fine sediment. Modelling of this lahar by numerical simulations allowed to calculate a flow depth of up to $1.7 \mathrm{~m}$. Satellite imagery revealed that the deposit observed in the field represents only $68 \%$ of the actual inundation area. Precipitation data indicates a 27-years return period for rains similar in magnitude to the one that triggered this lahar. Further detailed studies of secondary lahars will allow to better constrain hazard-scenarios at Popocatepetl volcano.

Key words: Secondary lahars; hazard; Popocatépetl; rain; erosion; mass wasting.

\section{INTRODUCCIÓN}

Los lahares son flujos constituidos por una mezcla de agua y sedimentos que descienden sobre las pendientes de un volcán debido a la fuerza de gravedad (Smith y Lowe, 1991), se pueden presentar de manera contemporánea a la actividad magmática, los cuales se denominan sin-eruptivos o, post-eruptivos, si ocurren en un periodo corto después de la erupción, dentro del periodo de respuesta del paisaje a la actividad eruptiva (Manville et al., 2009). Aquellos lahares que no tienen relación directa con la actividad eruptiva, se les denomina secundarios. Su estudio es relevante, ya que representan una de las mayores amenazas volcánicas, debido a que son procesos capaces de movilizar grandes volúmenes de sedimentos depositados en los flancos de edificios volcánicos, por lo que sus efectos pueden ser devastadores para las poblaciones asentadas en sus zonas de inundación. Por lo tanto, estudiar los mecanismos de generación, su magnitud, distribución y frecuencia en diferentes volcanes es indispensable para realizar una adecuada evaluación de peligro. 
En el registro geológico del volcán Popocatépetl existen evidencias de múltiples eventos de lahar, especialmente en la barranca Huiloac, ubicada en el sector noreste del volcán. Hasta el 2003, en esta barranca drenaban las aguas asociadas al derretimiento del glaciar, por lo que eran frecuentes los procesos de removilización de material volcánico asociados a la actividad eruptiva. Lahares sineruptivos ocurrieron en esta barranca en 1997 y 2001, asociados a la actividad explosiva del volcán (González et al., 1997; Capra et al., 2004 y Muñoz-Salinas et al., 2007, 2009 ). Debido a esto, estudios previos se enfocaron en este sector, ignorando otras áreas en las cuales también es posible la generación de lahares, incluyendo el flanco noroeste y el sector sur, como lo evidencian los trabajos de Sheridan et al. (2001) y Franco et al. (2016).

En este trabajo se presenta la reconstrucción del lahar ocurrido el 4 de febrero del 2010, en la barranca Nexpayantla, ubicada en el sector noroeste del volcán Popocatépetl, con la finalidad de documentar sus características incluyendo: el mecanismo de disparo, periodo de recurrencia e implicaciones del peligro asociado. Para este fin, se realizó un análisis geomorfológico y textural del depósito, integrado con el estudio de la precipitación y de imágenes de satélite ASTER para delimitar el área de inundación. Las profundidades de flujo se calcularon mediante simulaciones numéricas con el código numérico FLO-2D. Estudios de este tipo representan un avance en la caracterización de lahares secundarios en el volcán Popocatépetl, ya que la actividad explosiva actual influye en su generación, al aportar nuevo material inestable en las pendientes. Lo anterior, permitirá evaluaciones más precisas del peligro que representan para las comunidades asentadas en las posibles zonas de afectación y constituye un factor determinante en la prevención y mitigación del impacto de estos fenómenos.

\section{ÁREA DE ESTUDIO}

El volcán Popocatépetl (1903' N, 98³5' O, 5452 m s.n.m.) es un estratovolcán ubicado en la parte central del Cinturón Volcánico Transmexicano (Figura 1a). Se sitúa aproximadamente $65 \mathrm{~km}$ al sureste de la Ciudad de México y a $45 \mathrm{~km}$ al oeste de la ciudad de Puebla. Se estima que en un radio de $100 \mathrm{~km}$ alrededor del volcán, habitan más de 25 millones de personas por lo que representa el volcán de mayor riesgo en México (Espinasa-Pereña, 2014, 2018).

La barranca Nexpayantla se localiza en el flanco NW del volcán, cuenta con un área de $21.7 \mathrm{~km}^{2}$, una longitud aproximada de $18 \mathrm{~km}$ y un ancho de más de $100 \mathrm{~m}$ en promedio (Figura 1b). Sus paredes están constituidas por derrames de lava y domos que constituyen los rema-

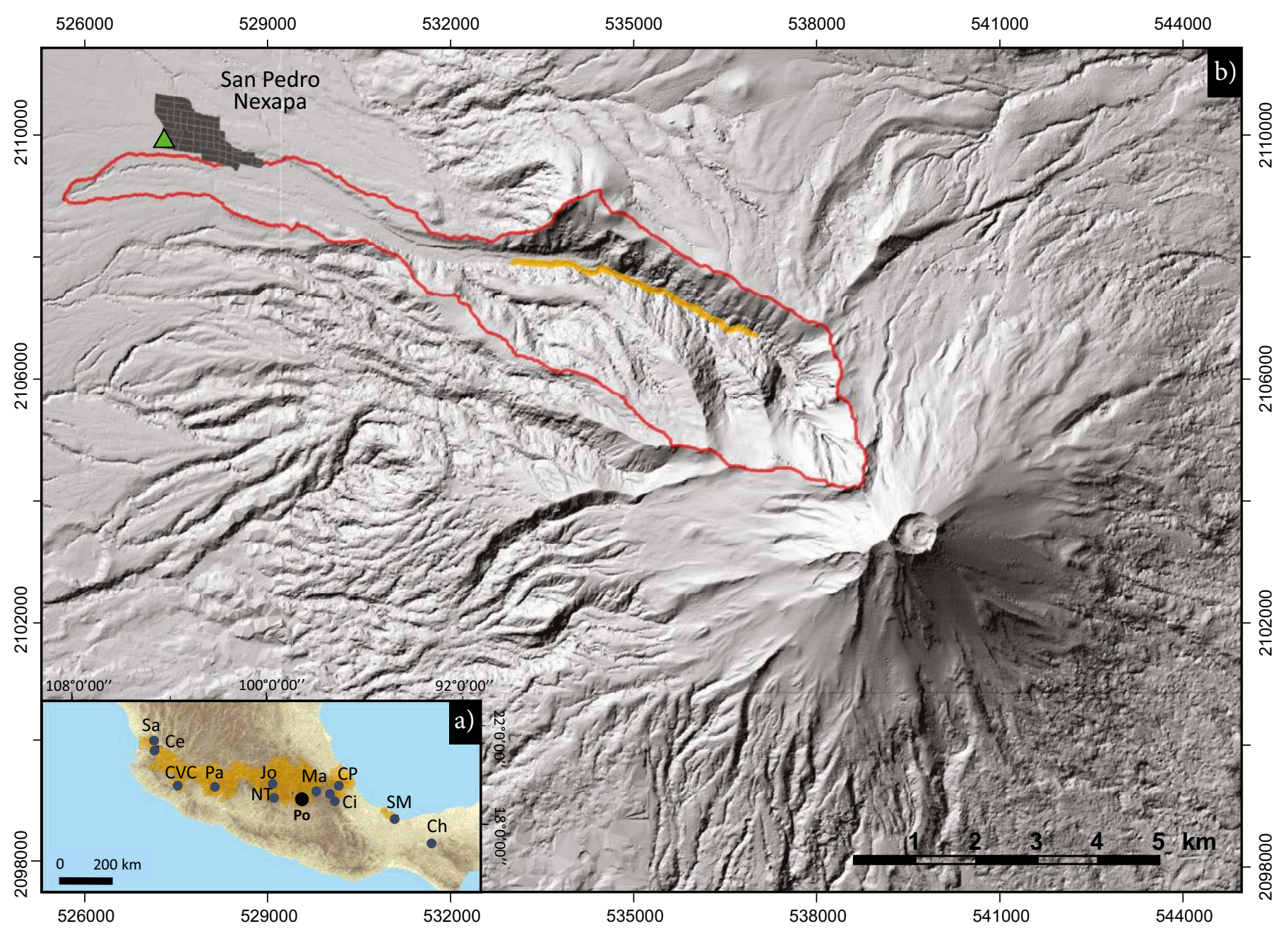

Figura 1. a) Mapa de localización del volcán Popocatépetl y su posición en la parte central de la Faja Volcánica Transmexicana. b) Ubicación de la cuenca Nexpayantla (delimitada con línea roja). El polígono naranja indica la distribución del lahar Nexpayantla. Po: Popocatépetl, Sa: Sangangüey, Ce: Ceboruco, CVC: Complejo Volcánico de Colima, Pa: Paricutín, NT: Nevado de Toluca, Jo: Jocotitlán, Ma: Malinche, Ci: Citlaltépetl, CP: Cofre de Perote, SM: San Martín, Ch: Chichonal. 
nentes de los edificios antiguos Nexpayantla y Ventorrillo, depósitos piroclásticos del edifico actual y depósitos glaciales (Espinasa-Pereña y Martín-Del Pozzo, 2006). La parte alta y media de la barranca se caracterizan por sus pendientes abruptas, mayores a $35^{\circ}$ (Figura 2), la presencia de cascadas de hasta decenas de metros de altura y el afloramiento de diques dacíticos en la ladera norte, que cortan lavas andesíticas y brechas piroclásticas (Delgado et al., 2017). En contraste, en la parte baja, la pendiente predominante en las paredes es menor a $15^{\circ}$ (Figura 2b). Esta distinción es fundamental, ya que las zonas de mayor pendiente definen una zona donde ocurren erosión laminar y procesos de inestabilidad de laderas, que son fuente de material para lahares como el lahar Nexpayantla. En contraste, la parte baja de la cuenca, delimita la zona de sedimentación para el material transportado, ya sea por corrientes fluviales o lahares (Figura 2b) y, en su desembocadura, se desarrolla un abanico aluvial sobre el cual se localiza el poblado de San Pedro Nexapa (Figura 1b).
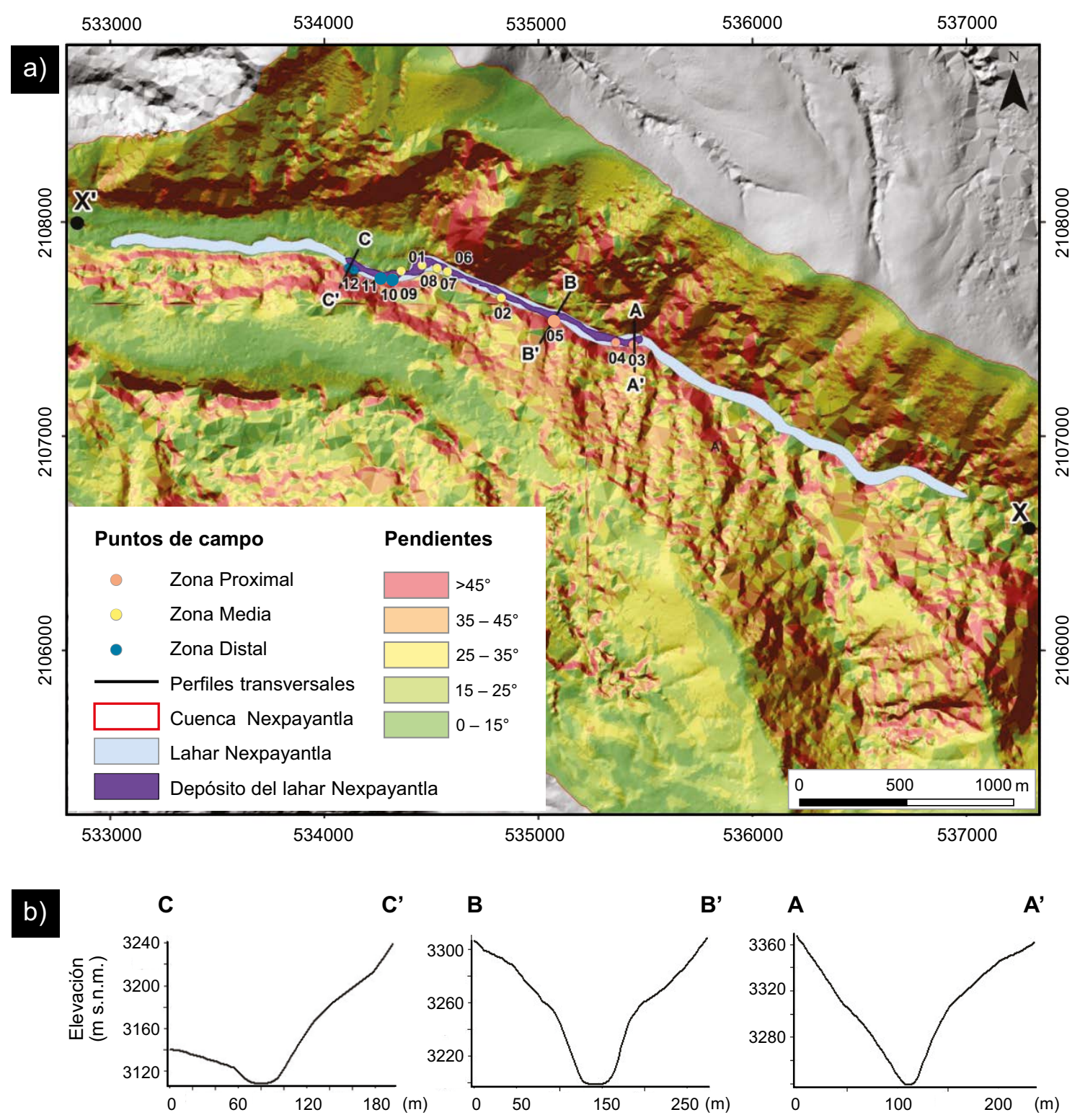

$\mathbf{X}^{\prime}$

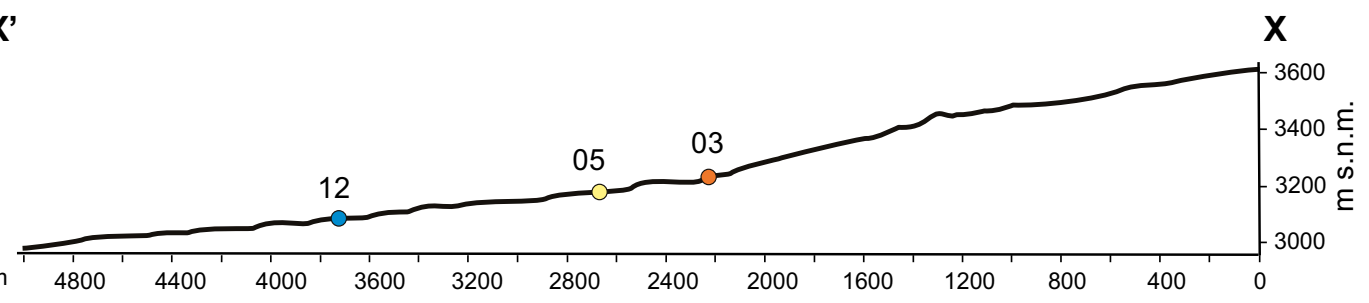

Figura 2. a) Mapa de pendientes de la cuenca Nexpayantla, el polígono azul indica la distribución del lahar Nexpayantla, el polígono morado muestra la distribución del depósito. b) Perfiles longitudinal (X-X') y transversales (A-A', B-B' y C-C') donde se observan los cambios en la pendiente y la geometría de la barranca. 


\section{LAHARES EN EL VOLCÁN POPOCATÉPETL}

Durante el Holoceno tardío, los tres periodos eruptivos principales del Popocatépetl (3195-2830 a.P., 800-215 a.P., y 675-1095 A.D.) estuvieron caracterizados por la formación de columnas plinianas, cuyo colapso provocó el bloqueo de la red hidrográfica del Popocatépetl (Siebe et al., 1996; Macías, 2005). Con la adición de agua procedente de la fusión de hielo y nieve (González et al., 1997), o de lluvias torrenciales (Macías, 2005), se generaban lahares que esparcieron la carga sedimentaria por la Cuenca de Puebla. Uno de los eventos de lahar mejor caracterizados del volcán es el lahar San Nicolás, que se produjo en la barranca Huiloac hace 1100-1300 años cal A.P (González, 2000). Este flujo, con un volumen de $4.2 \times 10^{7} \mathrm{~m}^{3}$, se asocia al derretimiento del glaciar y viajó aproximadamente $57 \mathrm{~km}$ hasta alcanzar la ciudad de Izúcar de Matamoros (Puebla). Otro evento de gran magnitud es el que reportan Sheridan et al. (2001) en la barranca de Nexpayantla, de una edad similar a la del lahar de San Nicolás. El depósito de este evento se encuentra a más de $15 \mathrm{~km}$ del volcán y se estima un volumen de $1.2 \times 10^{8} \mathrm{~m}^{3}$.

En el presente periodo eruptivo, iniciado en diciembre de 1994, los lahares principales han ocurrido en la barranca Huiloac en 1995, 1997 y 2001. En abril de 1995, una emisión cubrió de piroclastos aproximadamente el 50 \% del área del glaciar, lo que ocasionó su fusión repentina (Palacios et al., 2001). Dos años después, entre el 30 de junio y el 1 de julio de 1997, fuertes precipitaciones que se produjeron en las laderas del volcán removilizaron los sedimentos que se encontraban en el fondo de las barrancas y se generó un flujo hiperconcentrado (Sheridan et al., 2001). Al ir incorporando material, éste se transformó en un flujo de escombros, para después transformarse nuevamente en un flujo hiperconcentrado en la parte distal (Capra et al., 2004). Este lahar transportó $1.8 \times 10^{5} \mathrm{~m}^{3}$ de material sólido y agua (Muñoz-Salinas et al., 2009), alcanzó una velocidad entre 1.4 y $7.7 \mathrm{~m} / \mathrm{s}$ (Muñoz-Salinas et al., 2007) y tras $21 \mathrm{~km}$ de recorrido, se detuvo en la población de San Nicolás de los Ranchos.

Posteriormente, en el episodio eruptivo del 22 de enero de 2001, el volcán emitió un flujo piroclástico que recorrió $6 \mathrm{~km}$ en la ladera norte del volcán. Al interactuar con el glaciar, causó la liberación de agua subglaciar que saturó los materiales e inició un flujo de escombros que se desplazó por $14.3 \mathrm{~km}$, a lo largo de las barrancas Tenenepanco y Huiloac, y finalizó $2 \mathrm{~km}$ antes de alcanzar la población de Santiago Xalitzintla. El volumen transportado fue de $1.6 \times 10^{5} \mathrm{~m}^{3}$ (MuñozSalinas et al., 2009) y desarrolló velocidades comprendidas entre 1.3 y $13.8 \mathrm{~m} / \mathrm{s}$ (Muñoz-Salinas et al., 2007).

Franco et al. (2016) señalan que en el periodo de $1959 \mathrm{al} 2013 \mathrm{han}$ ocurrido 23 lahares en la barranca Nexpayantla, fechados por medio del método de dendrocronología y asociados al fenómeno de El Niño. Entre estos 23 eventos, se encuentra el lahar Nexpayantla, objetivo del presente trabajo.

Finalmente, el último lahar documentado ocurrió en el año 2017, en la barranca Hueyatlaco al NW del volcán. Este evento se originó por el efecto combinado del sismo M7.1 ocurrido el 19 de septiembre de dicho año y la removilización de suelos y material piroclástico depositado en los flancos del volcán por procesos de remoción en masa (Capra et al., 2018a; Coviello et al., 2020).

\section{MATERIALES Y MÉTODOS}

La caracterización del lahar se efectuó a partir del análisis de la precipitación, imágenes satelitales tipo ASTER, datos recolectados en campo y el análisis textural del depósito. Una vez definidos el origen y características del lahar, éste fue reproducido mediante simulaciones numéricas con el código FLO-2D (O’Brien, 2009) para el cálculo de profundidades de flujo, así como para la validación del modelo para lahares con características similares al lahar Nexpayantla.

\section{Fecha de ocurrencia del evento, análisis de la precipitación y periodo de recurrencia}

Para establecer la fecha de ocurrencia del lahar, que hasta antes de este estudio era desconocida, se analizaron los registros de precipitación diaria de las estaciones del Servicio Meteorológico Nacional en las áreas aledañas al volcán Popocatépetl (Figura 3), en particular de San Pedro Nexapa, durante el año 2010 que fue el año reportado para el evento (Martin del Pozzo et al., 2017). Una vez establecidas las fechas probables, se utilizaron imágenes satelitales tipo ASTER con una resolución espacial de $15 \mathrm{~m}$ (descargadas de la página https://ava.jpl. nasa.gov/index.php) para complementar la información obtenida en campo con respecto al origen y la distribución. Dichas imágenes tienen un nivel de procesamiento $1 \mathrm{~B}$, que incluye la calibración radiométrica y la corrección geométrica para igualar los valores de radianza. Por otro lado, para determinar el umbral de lluvia que dio origen al lahar Nexpayantla, se emplearon los datos pluviométricos normalizados, las medias y las extremas mensuales de la estación San Pedro Nexapa (CNA, SMN, 2015), que cuenta con el registro de precipitación diario de 1961 al 2014. El periodo de retorno (PR) para lluvias similares a la que disparó el lahar Nexpayantla, se estimó con la fórmula de Selby (1985).

$$
P R=\frac{n^{o} . \text { años de registro }+1}{n^{o} . \text { de mediciones individuales }}
$$

Esta fórmula se basa en un análisis estadístico de valores extremos y establece la probabilidad de ocurrencia de una precipitación de igual o mayor magnitud a la ocurrida en el 2010.

\section{Caracterización del evento y sus depósitos}

Las características del depósito se obtuvieron a partir de observaciones de campo y análisis granulométricos. La granulometría de las partículas gruesas $(\geq-3 \phi)$ se realizó por análisis de imágenes mediante el método de Rosiwal (Sarocchi et al., 2005) mientras que el tamizado seco se utilizó para las partículas con tamaños $<-3 \phi$. Debido a la poca cantidad de material fino presente en el depósito ( $<3 \mathrm{wt} \%)$, no se realizó análisis granulométrico de limo y arcilla.

\section{Simulación numérica y calibración del modelo}

La simulación numérica se realizó con el software FLO-2D (O’Brien, 2009), el cual es un modelo bidimensional de conservación de volumen, que permite simular flujos en topografías complejas y simula el movimiento de fluidos no-newtonianos como flujos hiperconcentrados y flujos de escombros.

La modelación matemática se logra integrando numéricamente la ecuación diferencial de continuidad (2) y la ecuación de movimiento (3) (O’Brien, 2009):

$$
\frac{\partial h}{\partial t}+\frac{\partial h V}{\partial x}=i
$$

La ecuación de continuidad (2) es un caso particular de la ecuación de conservación de la masa, donde $h$ es la profundidad hidráulica, $V$ es la componente de la velocidad en una de las ocho direcciones de desplazamiento $x$, $i$ es la intensidad de la lluvia y $t$ el tiempo.

La ecuación de movimiento en la dirección $\mathrm{x}$ es:

$$
S_{f_{x}}=S_{0_{x}}-\frac{\partial h}{\partial x}-\frac{V_{x}}{g} \frac{\partial V_{x}}{\partial x}-\frac{V_{y}}{g} \frac{\partial V_{x}}{\partial y}-\frac{1}{g} \frac{\partial V_{x}}{\partial t}
$$

Donde $S$ es la pendiente, $t$ el tiempo y $g$ la gravedad. 

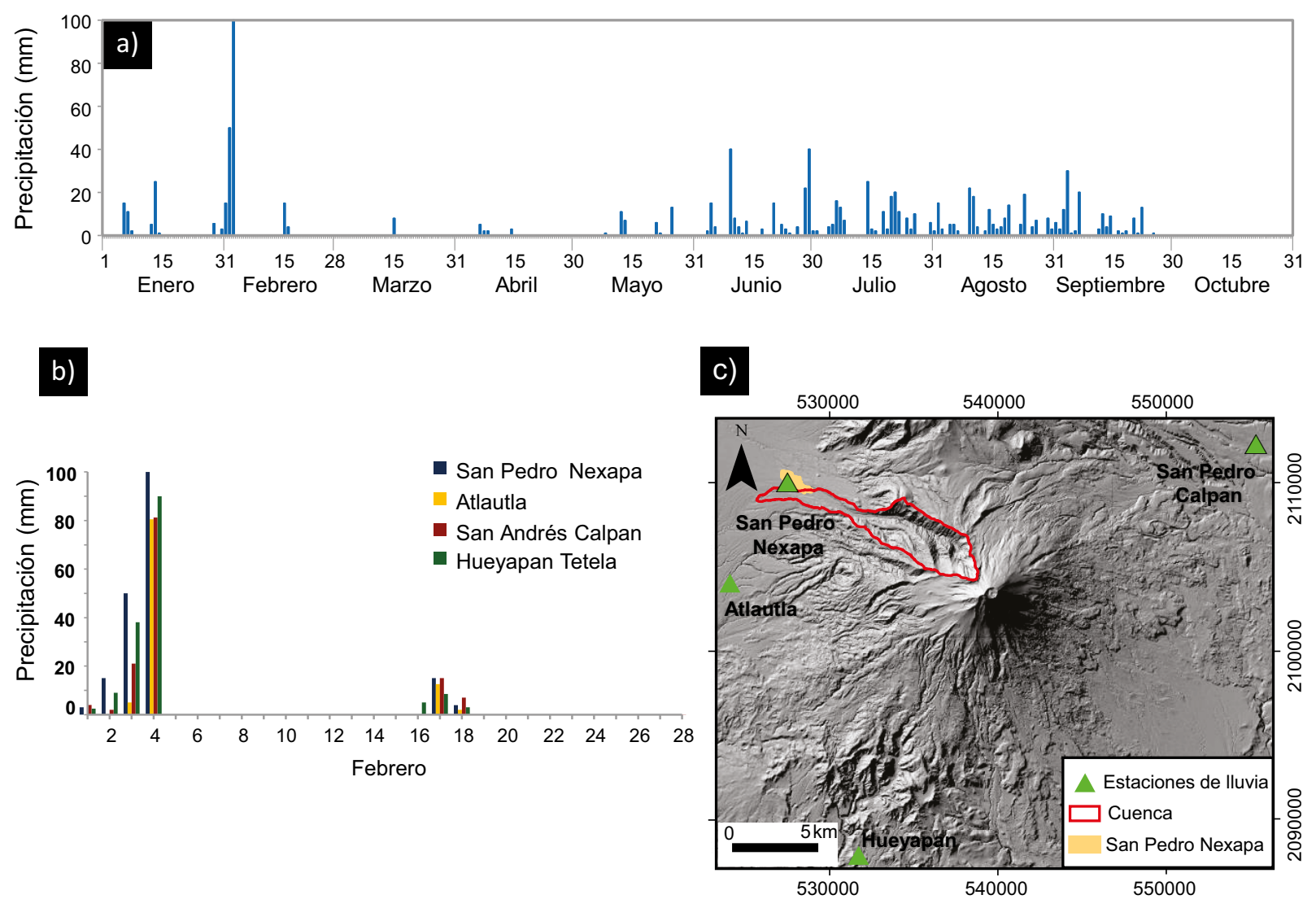

Figura 3. a) Gráfica de la precipitación medida en la estación San Pedro Nexapa, donde se observan las máximas precipitaciones registradas para el año 2010. El pico máximo anual se observa el día 04 de febrero. b) Datos de precipitación de las cuatro estaciones meteorológicas más cercanas al volcán Popocatépetl del mes de febrero. Las cuatro estaciones muestran precipitación por encima de los $80 \mathrm{~mm}$ para el día 04 de febrero. c) Ubicación de las estaciones meteorológicas.

Estas ecuaciones se resuelven por el método de diferencias finitas y permiten simular la trayectoria, el área de inundación, las profundidades de flujo y la velocidad.

Para calibrar el modelo mediante FLO-2D se requiere de: 1) Un modelo digital de elevación; 2) un hidrograma de entrada (sólidos + agua); 3) la rugosidad de la superficie (coeficiente de Manning); 4) dos coeficientes reológicos, $\alpha$ y $\beta$, relacionados a la resistencia crítica y la viscosidad del lahar, obtenidos a partir de datos empíricos obtenidos por O’Brien y Julien (1988) y; 5) la concentración de sedimentos.

El modelo digital de elevación utilizado para las simulaciones fue de $3 \mathrm{~m}$ de resolución y fue proporcionado por el Centro Nacional de Prevención de Desastres (CENAPRED).

Hidrograma. Para construir el hidrograma de entrada se utilizó un hidrograma unitario y, para estimar la descarga, se utilizó la relación empírica propuesta por Rickenmann (1999), que permite calcular el pico de descarga a partir del cálculo del volumen del depósito, con la relación:

$$
Q_{p}=0.00135 V^{0.870}
$$

El coeficiente de Manning $n$ se calculó a partir de las características de la barranca, mediante la fórmula (Phillips y Tadayon, 2006):

$$
n=\left(n_{0}+n_{1}+n_{2}+n_{3}+\ldots n_{n}\right) m
$$

Donde,

$$
\begin{aligned}
& n \text { : Coeficiente de Manning, } \\
& n_{0} \text { : Valor base para un canal regular (recto y uniforme), }
\end{aligned}
$$

$n_{1}$ : Grado de irregularidad de la superficie,

$n_{2}$ : Variación en la sección transversal del canal (forma y tamaño), $n_{3}$ : Obstrucciones u obstáculos al paso de flujos,

$n_{4}$ : Vegetación,

$m$ : sinuosidad a lo largo del canal.

Con base en la información obtenida en campo y en las imágenes ASTER, se calcularon valores diferentes de $n$ que variaron de 0.056 a 0.156 .

Los coeficientes reológicos utilizados fueron establecidos con base en los resultados del análisis textural realizado. Se utilizaron los valores $\alpha_{\eta}=0.0648$ y $\beta_{\eta}=6.20$ para la viscosidad, y para la resistencia crítica, se usaron valores $\alpha_{\tau}=0.0765$ y $\beta_{\tau}=16.9$, ambos se obtuvieron empíricamente por O’Brien y Julien (1988) para flujos con bajo contenido de material fino.

La concentración de sedimentos fue establecida con base en las características texturales del depósito y en el criterio de clasificación de Scott (1988) y Vallance y Scott (1997) que utiliza los valores de la media y la desviación estándar del depósito para diferenciar entre corrientes fluviales, flujos hiperconcentrados y de escombros.

Posteriormente, los resultados de la simulación se validaron cuantitativamente mediante tres parámetros: El porcentaje de la relación de longitud (PLR), la función "fitness" $\left(e_{1}\right)$ y la comparación de profundidades de flujo calculadas, contra espesores del depósito medidos en campo. Para evaluar la simulación mediante el parámetro PLR, se compara la longitud del flujo simulado y la longitud del flujo observado mediante la siguiente fórmula (Proietti et al., 2009): 


$$
P L R=\frac{L_{\text {sim }}}{L_{\text {obs }}} \times 100
$$

Donde $L_{\text {sim }}$ es la longitud del flujo simulado y $L_{o b s}$ es la longitud del flujo observado.

El segundo parámetro es la función "fitness" $\left(e_{1}\right)$, propuesta por Spataro et al. (2004), que compara el área del evento y la reproducida durante la simulación con la fórmula:

$$
e_{1}=\sqrt{\frac{m(R \cap S)}{m(R \cup S)}}
$$

Donde $m(R \cap S)$ es el área de traslape entre el flujo real y el flujo simulado y $m(R \cup S)$ es la suma del área subestimada, el área de traslape y el área sobreestimada entre el flujo real y el flujo simulado. Un valor de $e_{1}=1$ equivale a una coincidencia perfecta entre el evento real y la simulación, mientras que un valor de $e_{1}=0$ representa una discrepancia completa entre ambos.

\section{RESULTADOS}

\section{Mecanismo disparador y distribución del evento}

El lahar Nexpayantla fue un lahar disparado por lluvias (Martin del Pozzo et al., 2017), sin embargo, se desconocía la fecha exacta del evento, su magnitud y características. El análisis de la precipitación diaria durante el año 2010 en la estación San Pedro Nexapa, mostró que los días de mayor precipitación ocurrieron el 04 de febrero, 11 de junio y el 01 de julio (Figura 3a). El pico máximo de precipitación se registró el día 4 de febrero, donde se registraron $100 \mathrm{~mm}$. En las estaciones aledañas se registraron también lluvias intensas, de $90 \mathrm{~mm}$ en la estación Hueyapan; 81.5 mm, en San Andrés Calpan y; 80.5 mm, en Atlautla (Figuras 3b).

Las imágenes ASTER, antes y después del 04 de febrero, permitieron confirmar que este día fue la fecha de ocurrencia del evento. La Figura 4a muestra la imagen del 21 de enero de 2010, anterior a la ocurrencia del lahar. En ella se observa que la barranca se encuentra cubierta de vegetación, sin ningún signo de perturbación. En contraste, en la Figura 4b, que corresponde al día 26 de marzo de 2010, se muestra la distribución del lahar Nexpayantla y numerosos procesos de remoción en masa y marcas de erosión a lo largo de la barranca. El contraste de tonos entre ambas imágenes se debe a la diferencia del ángulo de inclinación del sol en ambas tomas. No obstante, este factor y la resolución de la imagen $(15 \mathrm{~m})$, es posible diferenciar los rasgos que se describen a continuación. El depósito asociado al lahar se encuentra a partir de la cicatriz con mayores dimensiones dentro de la barranca (indicado en la Figura $4 \mathrm{~b}$ con una estrella). Las imágenes de satélite muestran, aguas arriba de este punto, múltiples rasgos asociados a procesos de remoción en masa y evidencias del evento. Sin embargo, en campo no se identificaron depósitos de lahar en esta zona que se pudieran correlacionar. Finalmente, dichas imágenes muestran que el lahar tuvo una longitud de $4.5 \mathrm{~km}$ y cubrió un área de $222449 \mathrm{~m}^{2}$.

El trabajo de campo permitió observar que el depósito del lahar Nexpayantla tiene una extensión de $1.5 \mathrm{~km}$ y se distribuye en un área de $151851 \mathrm{~m}^{2}$. Los datos anteriores representan el $33 \%$ y el $68 \%$, respectivamente, de los medidos en las imágenes ASTER (Figura 2a).

El depósito se distingue como un cuerpo continuo (Figura 5a) o como terrazas aisladas ubicadas en los márgenes (Figura 5b), o la parte central de la barranca (Figura 5c), con una gran cantidad de troncos en su superficie y zonas de acumulación de bloques con soporte clasto a clasto (Figuras $5 \mathrm{~d}$ y $5 \mathrm{e}$ ). Está constituido por una sola unidad, es de color café, masivo, heterolitológico, con soporte de matriz arenosa y el contenido de limo y arcilla se encuentra por debajo del $3 \%$ wt (Tabla 1).
Su espesor varía de 0.45 a $1.28 \mathrm{~m}$. A partir del área y del espesor promedio $(0.71 \mathrm{~m})$, se calculó un volumen de $107814.5 \mathrm{~m}^{3}$, cuyo valor permitió estimar el pico de descarga en $32 \mathrm{~m}^{3} / \mathrm{s}$, el cual fue utilizado para calibrar la simulación numérica (Ecuación 4).

En función de la morfología de la barranca, la distribución del depósito y sus características texturales, se dividió en tres zonas: proximal, media y distal.

\section{Zona proximal}

La zona proximal incluye desde el inicio del lahar observado en las imágenes ASTER hasta el punto 05 , se caracteriza por un cauce recto en forma de " $\mathrm{V}$ ", con una pendiente promedio de $10^{\circ}$. El ancho del cauce es de $15 \mathrm{~m}$ y está limitado por paredes con una pendiente promedio de $50^{\circ}$ (Figura $2 \mathrm{a}$ y $2 \mathrm{~b}$ ), en donde se forman abundantes procesos de remoción en masa (Figura 6a). Hacia la cabecera de la cuenca existen cascadas de decenas de metros de altura y algunos desniveles formados por acumulación de bloques y troncos. El espesor del depósito en esta zona varía entre 0.45 y $0.92 \mathrm{~m}$ y está constituido por abundantes troncos con diámetro de hasta $0.5 \mathrm{~m}$. Los clastos de mayor tamaño se concentran en la cima del depósito y son de forma angulosa a subangulosa (Figura 6d).

Los resultados de los análisis texturales muestran histogramas granulométricos con distribución unimodal a polimodal, con modas variables en la fracción de la grava $(-9$ a $-3 \phi)$ y arena media $(0$ y $2 \phi)$ (Figura 7). Los parámetros estadísticos indican que el valor de la media (Mz) se encuentra entre - 0.47 y - 2.96 y la desviación estándar entre 2.37 y 3.20, lo que corresponde a depósitos muy pobremente seleccionados. El grado de asimetría (-0.34 a 0.09) indica curvas asimétricas, con un enriquecimiento hacia los tamaños gruesos y la curtosis $(0.68-2.09)$ representa curvas platicúrticas a muy leptocúrticas (Tabla 1).

Los parámetros estadísticos indican que, en la zona proximal, el depósito presenta características que lo ubican en un inicio en la zona de transición entre un flujo hiperconcentrado y flujos de escombros $y$, posteriormente, en el campo de los flujos de escombros (Figura 8).

\section{Zona media}

En la zona media, la barranca es sinuosa con una pendiente promedio de $6^{\circ}$, en sección transversal es de forma rectangular, con paredes abruptas, donde ocurren procesos de remoción en masa (Figura $6 \mathrm{~b}$ y 6c), su ancho es irregular y varía de 20 a 40 m (Figura 2). El depósito se caracteriza por una abundante concentración de troncos en la parte superior, que localmente pueden constituir la mayor parte del depósito (Figuras 5 a y $5 \mathrm{~d}$ ), además de la presencia de levees. En esta zona, los cortes verticales son escasos, sin embargo, en estos afloramientos, muestra una tendencia a la gradación normal, con clastos hasta $1 \mathrm{~m}$ en la parte superior y un aumento en el contenido de matriz (Figura 6e).

Los histogramas granulométricos muestran distribuciones unimodales y bimodales, con modas en $-4 \phi$ y $2 \phi$ (Figura 7 ). Los parámetros estadísticos indican valores de la media de -2 y 1.95 con un grado de selección 2.37 y 1.61 (Tabla 1). Este último representa el valor más bajo obtenido en todo el depósito. Sus características texturales, particularmente la media y la desviación estándar corresponden a un flujo hiperconcentrado y a la transición con un flujo de escombros (Figura 8).

\section{Zona distal}

En la zona distal la barranca es asimétrica, con una pendiente promedio de $4.8^{\circ}$, el ancho del cauce varia de 25 a $50 \mathrm{~m}$ y hay una gran abundancia de árboles y troncos sobre el cauce (Figura 2 a y b). En esta parte el depósito forma terrazas bien definidas o aisladas (Figura 5c), con un espesor de 0.47 a $1.28 \mathrm{~m}$. Asociadas a las terrazas, existen zonas de acumulación de bloques y troncos como se muestra en la Figura 5e. El tamaño máximo de los clastos dentro de las terrazas es de $0.38 \mathrm{~m}$ 

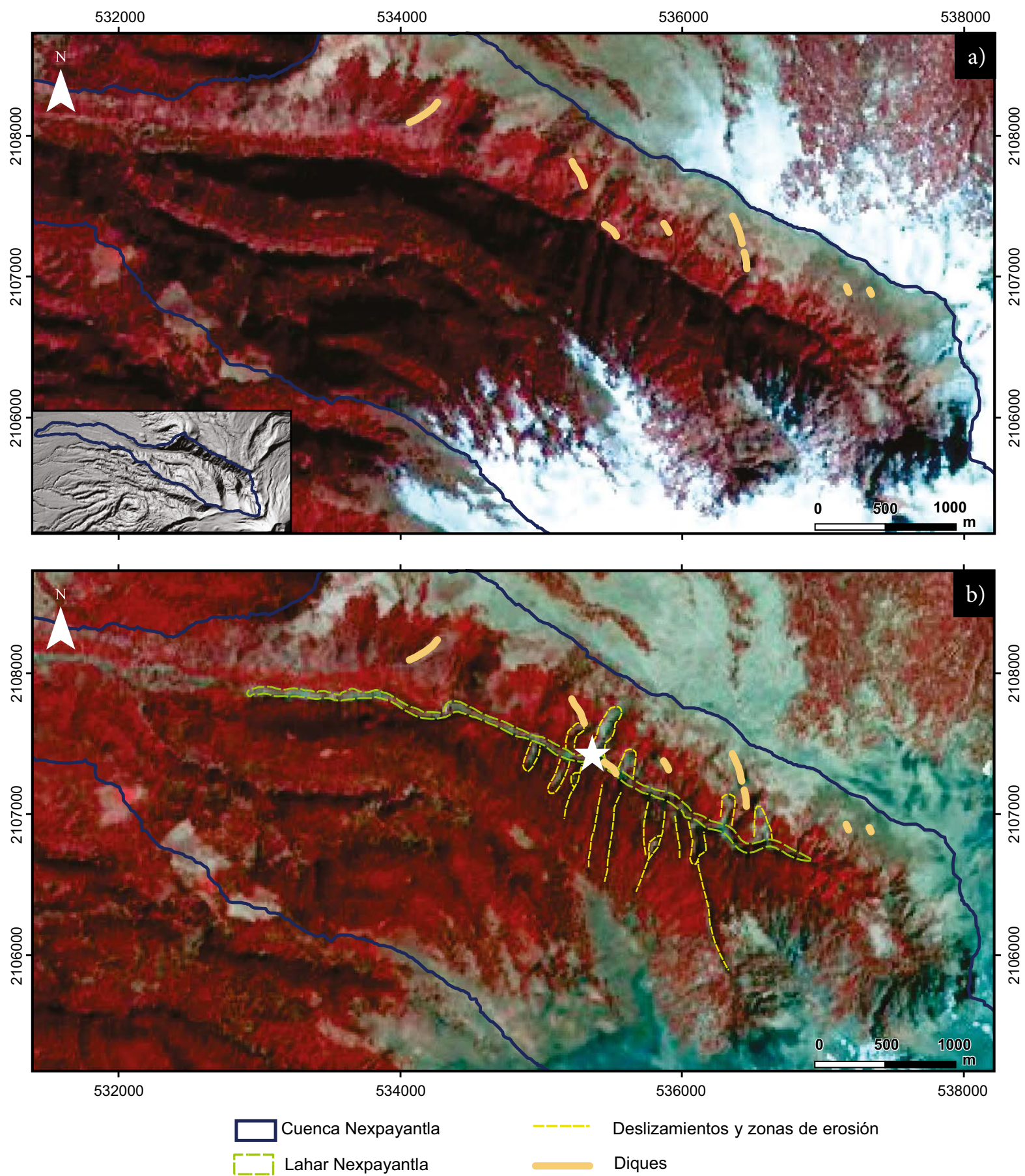

Figura 4. Imágenes ASTER subsistema VNIR en combinación de bandas 1, 2, 3 N Y. a) 21 de enero del año 2010, antes de la ocurrencia del lahar, se observa la barranca Nexpayantla cubierta de vegetación, sin ningún tipo de perturbación. b) 26 de marzo del año 2010, después del evento del lahar Nexpayantla, se observa el área inundada por el lahar y múltiples procesos de remoción en masa y zonas de erosión asociados al evento. La estrella blanca indica el proceso de remoción de masa de mayor dimensión, a partir del cual se encuentra el depósito del lahar Nexpayantla.

y, hacia el final del depósito, éstos presentan imbricación (Figura 6e).

Los histogramas granulométricos presentan distribuciones bimodales con modas variables, de $-3 \phi$ y $-7 \phi$ en la fracción de la grava, y de $2 \phi$ y $0 \phi$ en la fracción arenosa. Los valores de la media disminuyen ligeramente con respecto a la zona proximal (-2.09 a -0.91) y aumenta el contenido de arena. La desviación estándar aumenta (2.24 a 3.68), por lo que el grado de selección disminuye. El grado de asimetría arrojó valores que van de lo altamente asimétrico grueso a lo asimétrico fino
$(-0.67$ a 0.27$)$ y los valores de la curtosis $(0.64$ a 0.69$)$ nos indican que se trata de curvas platicúrticas (Tabla 1). Con base en estos datos, en la zona distal, el depósito muestra características de un flujo de escombros y, en el último punto, se ubica en la transición a un flujo hiperconcetrado (Figura 8).

En conclusión, cuando el lahar Nexpayantla tenía una concentración de sedimentos en el rango de un flujo de escombros, su depósito se caracteriza por la concentración de clastos gruesos en la cima del 

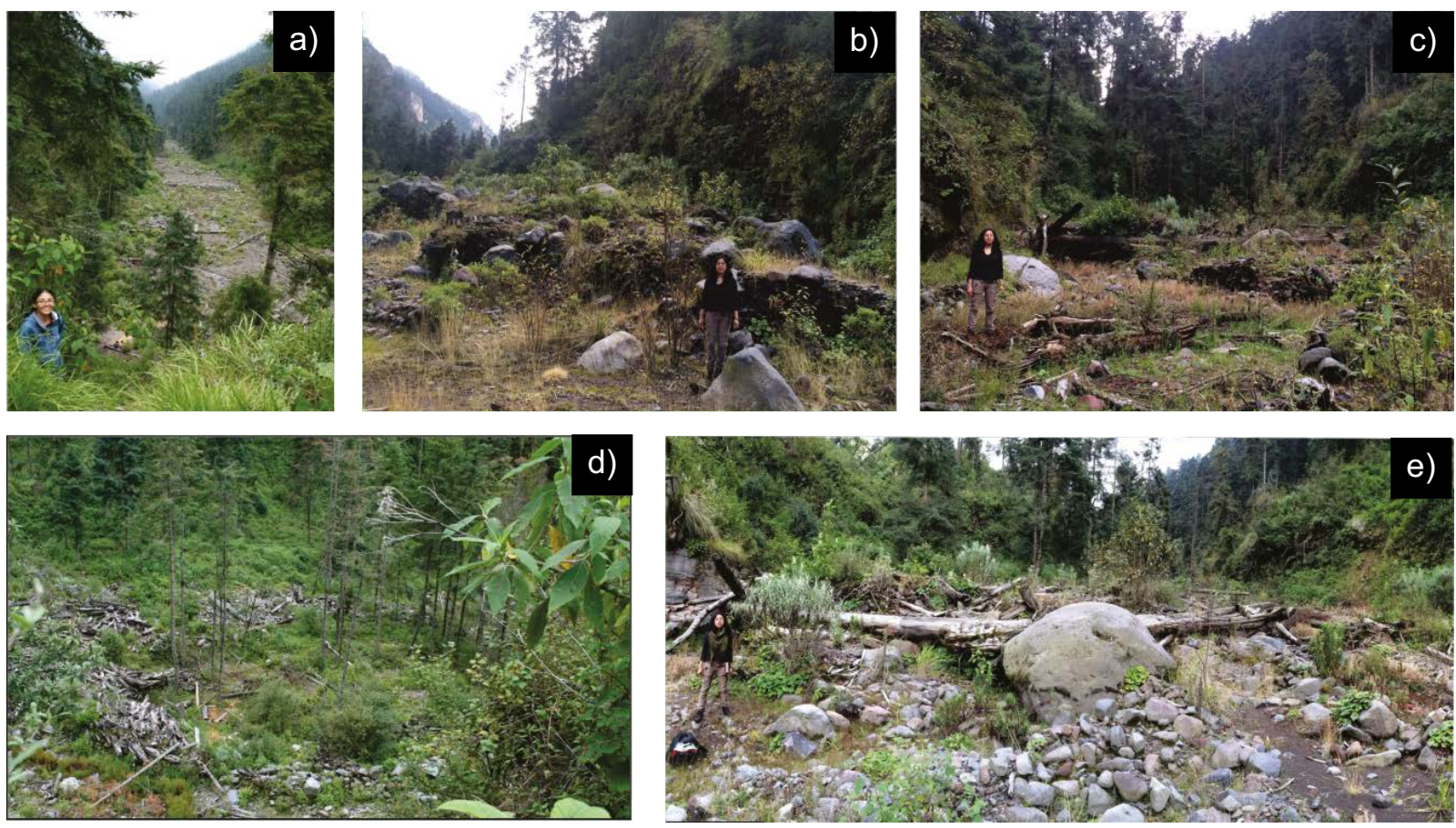

Figura 5. Fotografías del depósito del lahar Nexpayantla. a) Vista de la zona media donde se observa un cuerpo continuo, cuya superficie está compuesta por gran cantidad de troncos de árboles. b) Terraza formada por el lahar en la zona proximal, la cima del depósito se caracteriza por la concentración de bloques (punto 03). c) Remanente del depósito en la sección central de la barranca en la zona distal. d) Superficie del depósito compuesta por abundantes troncos de árboles (punto 08). e) Zona distal del depósito donde es notable la presencia de bloques con soporte clasto a clasto (punto 11).

depósito, distribuciones granulométricas bimodales a polimodales, con valores altos en la media $(>-2)$ y la desviación estándar $(>3)$. En cambio, cuando la concentración se encontraba en el rango de un flujo hiperconcentrado, el depósito muestra una tendencia a la gradación normal, distribuciones granulométricas unimodales, con valores bajos de la media $(<-2)$ y la desviación estándar $(<2.37)$. Por último, en las zonas que correspondieron con una corriente fluvial, sus depósitos no se distinguen de sedimentos fluviales anteriores, por lo que sólo se identificó su distribución únicamente en las imágenes ASTER.

\section{Simulación numérica del Lahar Nexpayantla: Profundidades de flujo}

El lahar Nexpayantla se simuló con el modelo FLO-2D (O’Brien, 2009) para calcular la profundidad de flujo. Se utilizaron 3 parámetros (longitud, área y profundidad) para evaluar la precisión con la que el modelo reprodujo el evento del 2010. La cuantificación del error en la longitud del flujo se obtuvo a partir de la comparación entre el flujo simulado y el flujo delimitado en imágenes ASTER, con el parámetro PLR (Ecuación 6; Proietti et al., 2009). El resultado fue de 95 \%. Esto indica que la distancia recorrida por el lahar simulado se subestimó en un $5 \%$.

$$
P L R=\frac{L_{\text {sim }}}{L_{\text {ASTER }}}=\frac{4.3 \mathrm{~km}}{4.5 \mathrm{~km}} \times 100=95 \%
$$

Para el segundo parámetro, la función de ajuste $\mathrm{e}_{1}$, calculada entre el área de simulación y el área del lahar delimitado en ASTER fue de 0.72 (Ecuación 7), lo que indica que el área de inundación reproducida por el FLO-2D, reproduce en un $72 \%$ el área delimitada a partir de imágenes ASTER (Figura 9).

$$
e_{1 \text { Simu } u_{\text {ASTRR }}}=\sqrt{\frac{m(R \cap S)}{m(R \cap S)}}=\sqrt{\frac{185770.06}{361444.13}}=0.72
$$

En relación con la profundidad, los cálculos variaron entre 0.5 y $1.7 \mathrm{~m}$,

Tabla 1. Espesor y características granulométricas del depósito del lahar Nexpayantla.

\begin{tabular}{lccccccc}
\hline Sección & $\begin{array}{c}\text { Espesor } \\
(\mathrm{m})\end{array}$ & $\begin{array}{c}\text { Media } \\
(\mathrm{Mz})\end{array}$ & $\begin{array}{c}\text { Desviación } \\
\text { estándar }(\mathrm{s})\end{array}$ & Asimetría & Curtosis & Tipo de histograma & Zona \\
\hline $15-03$ & 0.45 & -0.47 & 2.37 & -0.34 & 0.68 & Unimodal & Proximal \\
$15-04$ & 0.92 & -2.96 & 3.01 & 0.28 & 2.09 & Polimodal & Proximal \\
$15-05$ & 0.62 & -2.29 & 3.20 & 0.09 & 0.84 & Polimodal & Proximal \\
$15-02$ & 0.70 & -2.01 & 2.37 & 0.40 & 0.56 & Unimodal & Media \\
$15-07$ & 0.42 & 1.95 & 1.61 & 0.01 & 1.64 & Unimodal & Media \\
$15-09$ & 0.86 & -1.43 & 3.53 & -0.46 & 0.67 & Bimodal & Distal \\
$15-10$ & 1.28 & -0.91 & 3.68 & -0.67 & 0.64 & Bimodal & Distal \\
$15-11$ & 0.47 & -2.09 & 2.24 & 0.27 & 0.69 & Unimodal & Distal \\
\hline
\end{tabular}


los valores más altos se ubican en la parte proximal y media, donde la barranca es más angosta. Las profundidades calculadas consideran el sedimento más agua, por lo que la línea de inundación debe de estar siempre por encima del depósito (Figura 10). En el caso de flujos hiperconcentrados, la concentración de sedimentos establecida fue de $0.2 \mathrm{y}$ 0.5 y, en el caso de flujos de escombros, la concentración mínima establecida fue de 0.5 y 0.6 (Beverage y Culbertson, 1964; Vallance y Scott, 1997; Zanuttigh y Lamberti, 2007). Los puntos ubicados en la transición entre flujos de escombros e hiperconcentrados fueron asignados con una concentración 0.5 . Se consideraron válidos los resultados, cuando la profundidad calculada por el código FLO-2D, estuviera dentro del rango establecido para la concentración de sedimentos obtenida a partir del espesor del depósito y los análisis texturales y aceptando un $\pm 10 \%$ de variación en el cálculo (Tabla 2; Figuras 8 y 10).

Las profundidades calculadas en la parte más alta de la cuenca fueron de 0.5 a $1 \mathrm{~m}$; aproximadamente a los $2 \mathrm{~km}$, en la sección comprendida entre los puntos de campo 03 a 08 (zona proximal y media del depósito), la profundidad calculada aumenta hasta $1.5 \mathrm{~m}$ y, en las zonas más estrechas de la barranca, alcanza $1.7 \mathrm{~m}$. Posteriormente, en la zona distal, la profundidad disminuye a $0.5-1 \mathrm{~m}$. Finalmente, en la parte más distal del lahar, donde ya no se encuentra el depósito, la profundidad estimada por el código disminuye hasta $<0.5 \mathrm{~m}$.

Los resultados de las simulaciones indican que, de los 10 puntos de campo utilizados para la validación, 6 de las profundidades calculadas a partir de las características del depósito y el código numérico, se encuentran en el mismo rango y el mejor ajuste fue en la zona proximal y media del lahar. En contraste, las mayores diferencias se encuentran en la transición entre la zona media y distal, en el cambio de morfología de la barranca, en donde el código subestima en más del 50\% la profundidad (Tabla 2; Figura 10).

Cabe mencionar que las mayores diferencias entre las imágenes de satélite, los datos de campo y los resultados de la simulación numérica, tanto en el área de inundación como en las profundidades de flujo, se observan en las zonas de curvatura de la barranca Nexpayantla (Figuras 9 y 10).

\section{DISCUSIÓN}

El lahar Nexpayantla se originó a partir de lluvias con una precipitación de $100 \mathrm{~mm}$ /día, ocurridas el 4 de febrero del 2010, durante la temporada seca, como lo indica el análisis de precipitación (Figura 3)
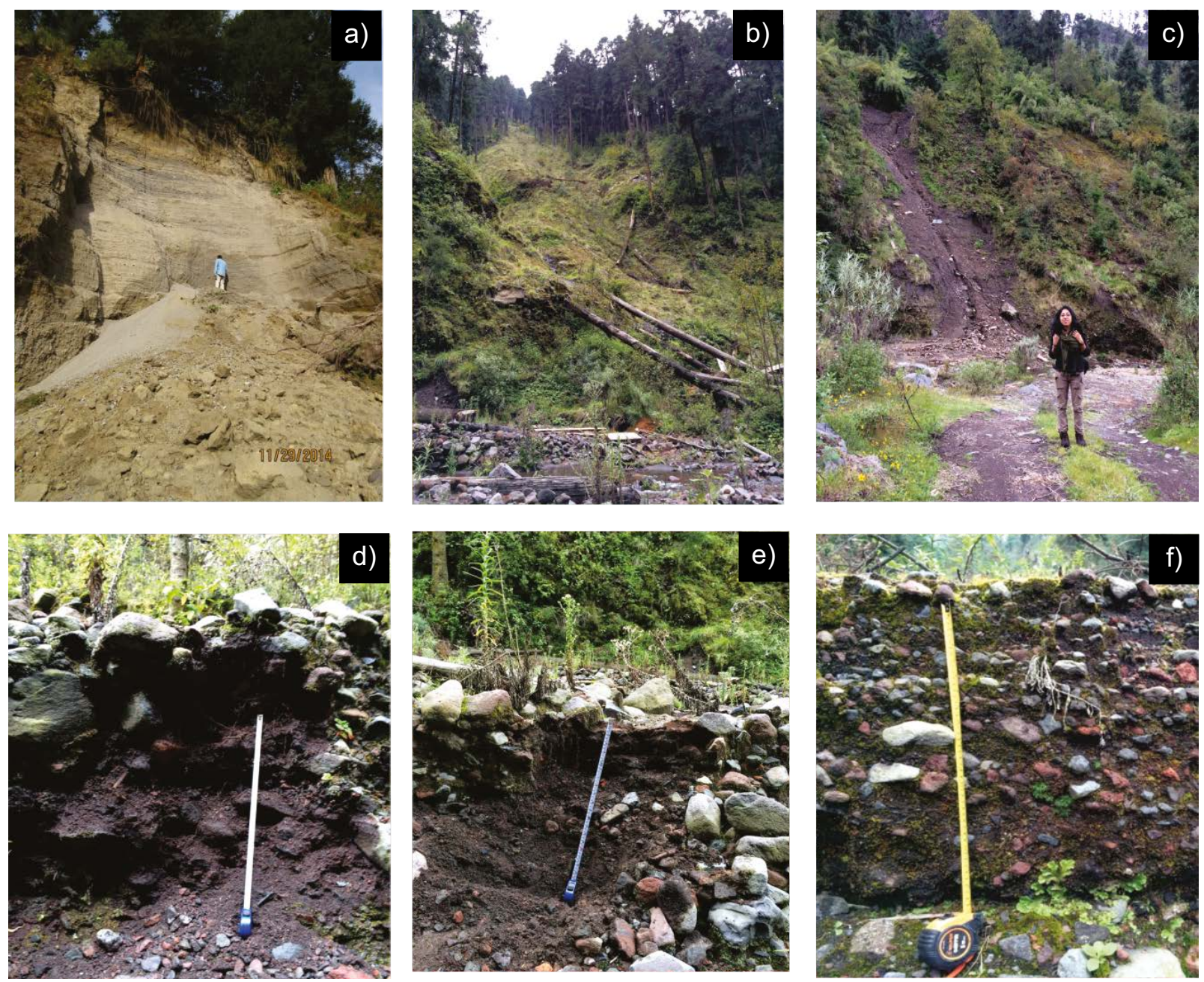

Figura 6. Fotografías de los procesos de remoción en masa ubicados en la barranca Nexpayantla, similares a los que alimentaron el lahar del 2010. a) Zona proximal, b y c) Zona media. d) Terraza formada por el lahar en la zona proximal, se observa la concentración de bloques en la parte superior del depósito (punto 04). e) Depósito en la zona media, con un abundante contenido de matriz (punto 07).f) Fotografía del depósito en la zona distal (punto 11), es notable la presencia de zonas con soporte clasto a clasto y la presencia de imbricación. La ubicación de los puntos de campo se encuentra en la Figura 2. 
y las imágenes ASTER (Figura 4). Estas lluvias, saturaron porciones del terreno con pendientes abruptas, generalmente de más de $45^{\circ}$ (Figura 2) e indujeron erosión laminar de sedimentos en la superficie y numerosos procesos de remoción en masa superficiales, cuyo material fue depositado en la barranca y removilizado por el agua que fluía dentro de ella.

La distribución del lahar, comparada con la limitada distribución del depósito, así como sus características texturales al inicio y final, indican que el evento inició y finalizó como una corriente fluvial, cuyos depósitos no son identificables en campo. La ausencia en el registro sedimentario en las zonas que corresponden a una corriente fluvial, se debe a que los sedimentos depositados no se distinguen de sedimentos fluviales anteriores y a la poca profundidad de la corriente $(<1 \mathrm{~m})$, de acuerdo con los cálculos estimados a partir de la simulación numérica. Dicha corriente, incorporó material acumulado en el cauce por los numerosos procesos de remoción en masa que ocurrieron simultáneamente (Figura $4 \mathrm{~b}$ ), y se transformó progresivamente a un flujo de escombros (Figura 8). Debido a la sedimentación y/o la incorporación de agua, se transformó en un flujo hiperconcentrado en la zona media, para transformarse nuevamente en un flujo de escombros en la zona distal. La presencia de zonas con soporte clasto a clasto, la imbricación de clastos, y la granulometría del depósito apuntan a que el lahar finalizó como una corriente diluida. Por lo tanto, el lahar Nexpayantla se comportó como un flujo inestable con concentraciones variables de sedimentos, debido a procesos de erosión y sedimentación, asociados a: (1) cambios morfológicos de la barranca, como el ancho y la pendiente del canal, así como a la presencia de cascadas que focalizaron la erosión aguas arriba y la sedimentación aguas abajo (Procter et al., 2010), (2) a la presencia de sedimentos susceptibles a la erosión, (3) a la gran cantidad de troncos incorporados que constituyeron el lahar, los cuales modificaron la distancia alcanzada y la velocidad del flujo (Lancaster et al., 2003) y, probablemente, (4) a variaciones en la intensidad de la lluvia.

Las transiciones entre los diferentes tipos de flujo y el hecho de que la longitud y extensión del depósito subestimen la distribución real, son un punto importante de discusión en la evaluación del peligro, ya que la magnitud de muchos lahares se calcula con base en los depósitos observados en campo, lo cual puede conducir a subestimar la magnitud de lahares antiguos, así como de los escenarios posibles en un volcán determinado.

En lo relacionado a la reproducción del evento con base en simulaciones numéricas, el alcance y áreas de inundación, fueron reproducidas adecuadamente con el modelo. Sin embargo, el cálculo de la profundidad representó una buena aproximación sólo en la
05

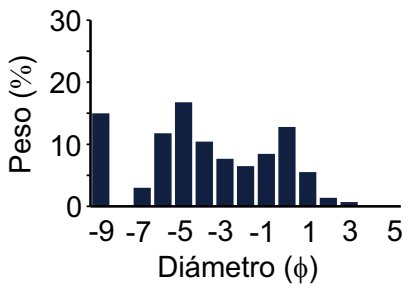

04

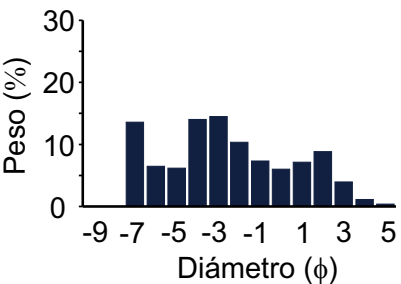

03

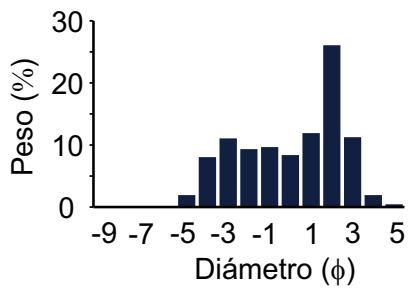

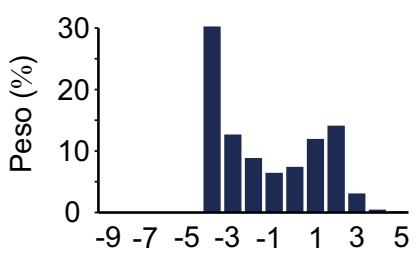

07

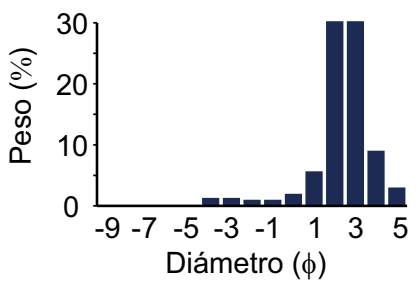

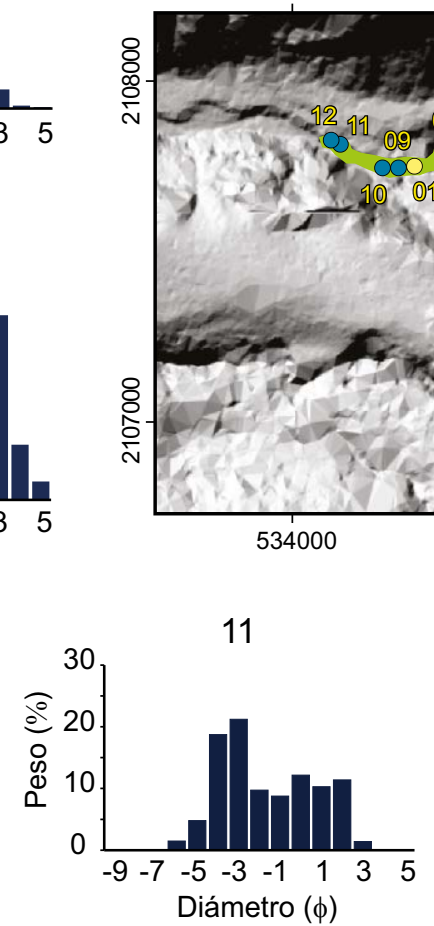

535000

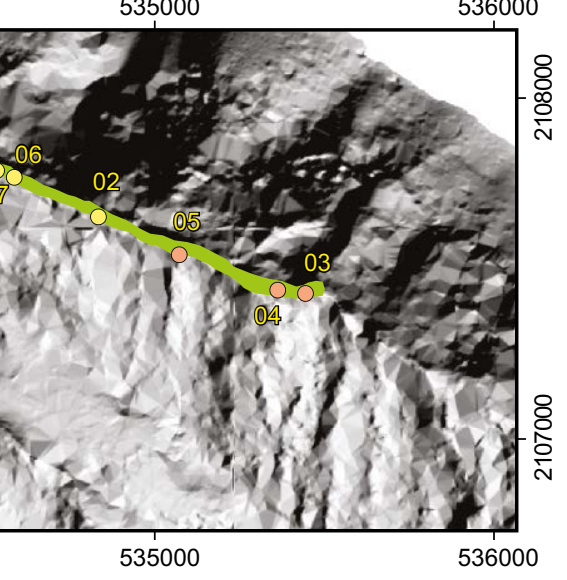

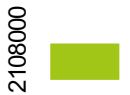

Depósito del lahar Nexpayantla

Puntos de campo

- Zona proximal

- Zona media

- Zona distal
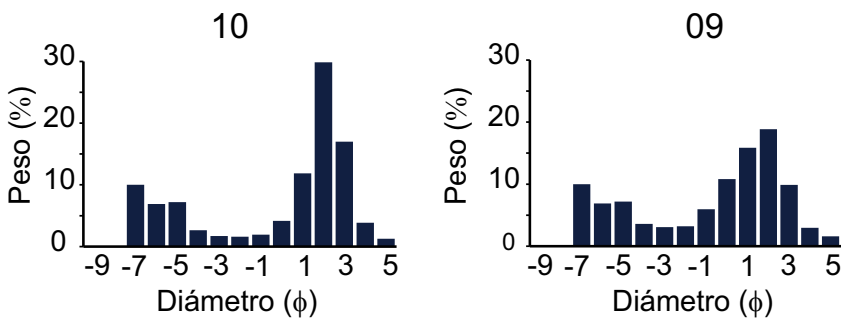

Figura 7. Distribución del depósito del lahar Nexpayantla y características granulométricas en las zonas proximal, media y distal. 


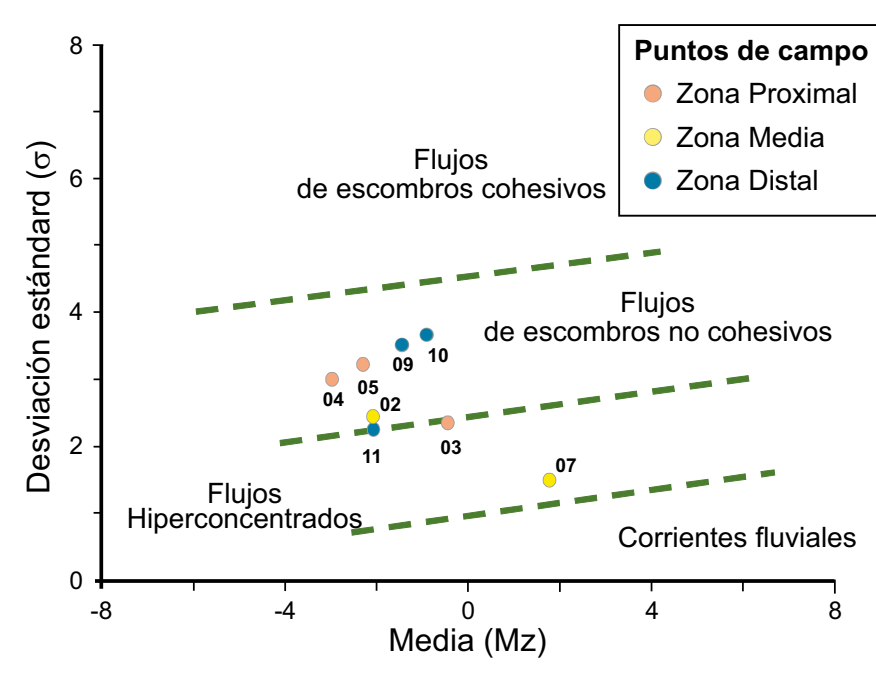

Figura 8. Clasificación del lahar Nexpayantla con base en sus características granulométricas (Vallance y Scott, 1997 ; Scott, 1988). zona proximal y media, si comparamos el espesor del depósito con la profundidad calculada. En contraste, la profundidad del lahar fue subestimada a partir de la transición entre la zona distal, y en zonas de curvatura de la barranca. Esto se puede deber a la resolución del modelo digital de elevación, así como a las limitaciones del modelo para reproducir la influencia de los troncos en la cinemática del flujo (Lancaster et al., 2003) y lahares que presentan rápidas transiciones de corrientes fluviales a flujos de escombros y viceversa. Por lo tanto, al reproducir eventos pasados con base en simulaciones numéricas, la interpretación de los resultados, especialmente en la evaluación del peligro, debe considerar estos factores.

\section{Análisis de la precipitación y periodo de recurrencia de eventos similares}

En el estudio de lahares secundarios y sus mecanismos disparadores, las características de la precipitación como duración, intensidad y cantidad de lluvia acumulada son los aspectos más importantes para evaluar en zonas susceptibles a su generación (Capra et al., 2010). Diversos autores han realizado estudios de esta índole en varios volcanes del mundo, llegando a establecer umbrales en la intensidad de

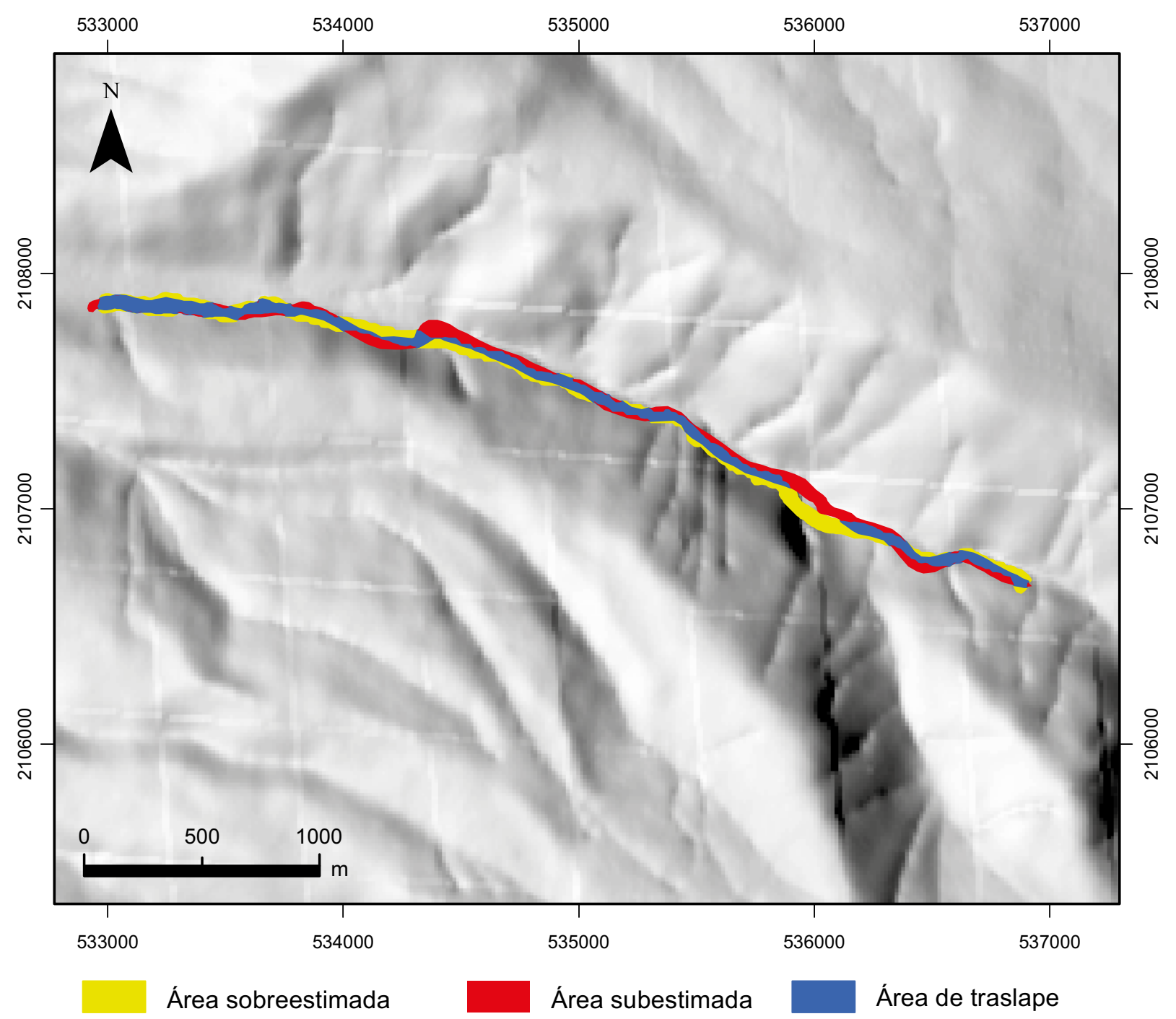

Figura 9. Diferencias observadas entre el área de distribución del lahar obtenida de las imágenes ASTER y la simulación numérica para el cálculo del parámetro $e_{1}$. En azul se muestra el área de traslape entre ambas, en rojo el área subestimada y en amarillo el área sobreestimada por la simulación. 

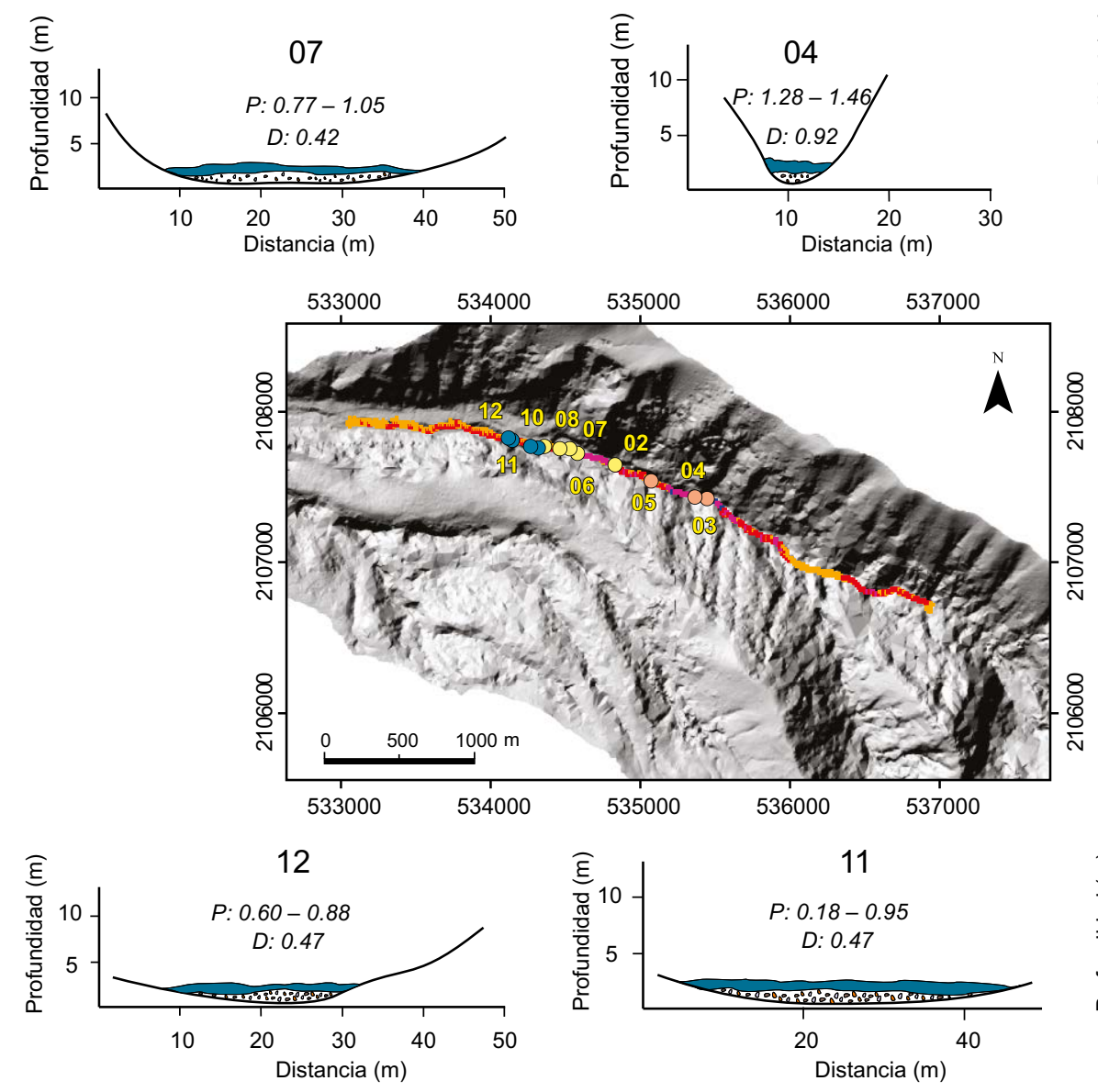

Figura 10. Resultados de la simulación del lahar Nexpayantla para la profundidad del flujo. Los perfiles comparan las profundidades del flujo calculadas por FLO-2D con datos recopilados en campo. P: Profundidad calculada por el modelo. D: Espesor del depósito.

la precipitación desde $0.41 \mathrm{~mm} /$ hora en la Isla Monserrat (Barclay et al., 2007) hasta $33 \mathrm{~mm} /$ hora en el volcán Merapi, Indonesia (Lavigne, 1998). Para el caso de México, Vázquez et al. (2014) señalan precipitaciones máximas de $95 \mathrm{~mm} / \mathrm{h}$ en el volcán de Colima. Estos datos muestran que la generación de lahares secundarios depende de las características de la precipitación (Capra et al., 2010;2018b) y de factores como la pendiente, la humedad previa del suelo, las características de la vegetación y de las propiedades físicas de los materiales (porosidad y permeabilidad).

En el caso del volcán Popocatépetl, sólo se cuenta con datos de precipitación diarios por lo cual no es posible establecer la intensidad de lluvia. Sin embargo, con base en los datos de lluvia obtenidos en la estación de San Pedro Nexapa (2620 m s.n.m.) se observó que durante el periodo 1961-2014 (CNA-SMN. 2015), sólo se registraron precipitaciones similares en dos ocasiones, una en 1981 con un registro de 141.5 $\mathrm{mm}$ y los $100 \mathrm{~mm}$ del año 2010. Aplicando la fórmula propuesta por Selby (1985), se encontró que el periodo de recurrencia (Ecuación 1) es de 27 años para una precipitación de al menos, la misma magnitud.

$$
P R=\frac{n^{o} \text {. años de registro }+1}{n^{o} . \text { de mediciones individuales }}=\frac{54}{2}=27
$$

Sin embargo, este resultado se obtuvo con datos de una estación ubicada a $12 \mathrm{~km}$ de la cabecera de la cuenca, con una diferencia de altitud de $2300 \mathrm{~m}$, y una resolución de 24 horas.

En lo relacionado con el registro geológico, Franco et al. (2016) a partir de un análisis dendrogeomorfológico, encontraron que existen
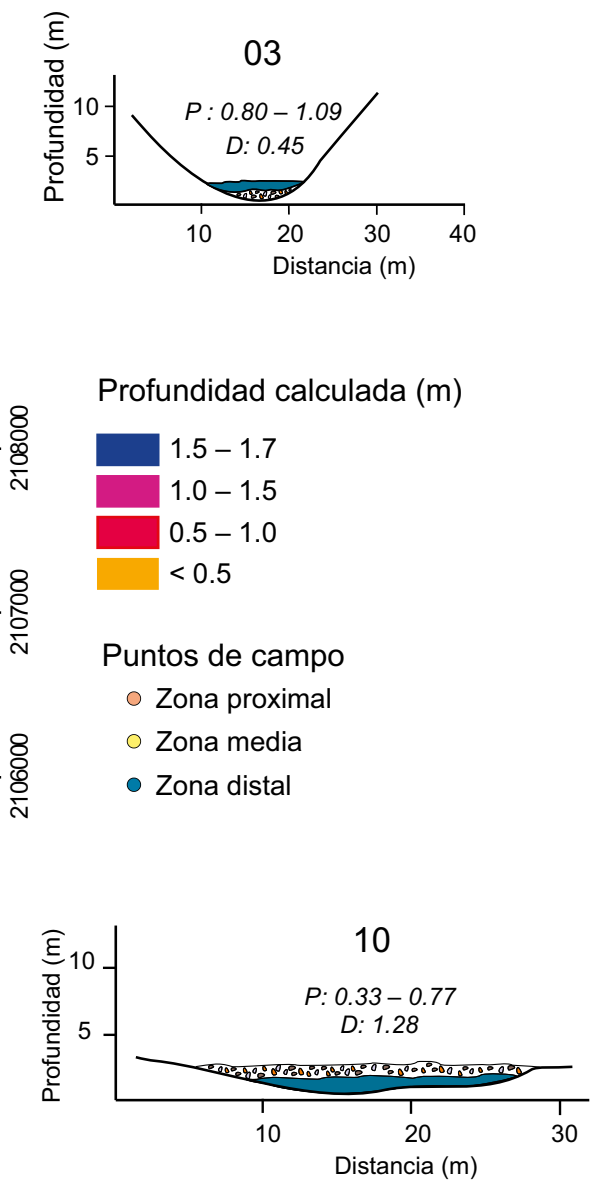

Puntos de campo

- Zona proximal

- Zona media

- Zona distal evidencias de al menos 23 eventos ocurridos desde 1959 al 2013, asociados a lahares secundarios, lo que indica un periodo de recurrencia de 2.3 eventos por año. Sin embargo, como se mencionó en el párrafo anterior, el periodo de retorno para lluvias similares a las que dispararon el lahar de Nexpayantla es de 27 años. Por lo tanto, para establecer la duración, magnitud e intensidad de la lluvia necesaria para generar lahares en la barranca Nexpayantla y su periodo de retorno, se requiere de datos con mayor resolución y de una red más densa de estaciones meteorológicas ya que, por efectos orográficos, las lluvias al inicio de la temporada pueden ser muy localizadas. Asimismo, la tala de árboles e incendios en la parte alta de la cuenca son factores que podría acelerar o intensificar los procesos erosivos y de remoción en masa dentro de la barranca Nexpayantla, lo que podría favorecer la formación de lahares en el futuro, ya que éstos sirven de fuente de sedimentos para ser removilizados durante precipitaciones intensas (Ramírez de la O., 2005).

Otro factor importante es que, aun cuando el lahar se considera de pequeña magnitud, llegó a $4 \mathrm{~km}$ de la población de San Pedro Nexapa, con 4633 habitantes, y un evento más grande podría causar daños importantes a esta población, ya que esta se encuentra asentada sobre un abanico constituido por depósitos fluviales y de lahar (Franco et al. 2016). Además, la barranca no se encuentra monitoreada y esto aumenta el riesgo, ya que dentro de ella diariamente hay personas que trabajan en la explotación de madera, que pueden ser afectadas por un evento similar. Finalmente, el depósito subestima la magnitud del evento en más del $50 \%$, lo cual no se hubiera podido identificar 
Tabla 2. Profundidades calculadas por la simulación numérica y profundidades esperadas con base en la concentración de sedimentos y espesor del depósito. FE: Flujo de escombros. FH: Flujo hiperconcentrado.

\begin{tabular}{|c|c|c|c|c|c|}
\hline 苞 & $\begin{array}{c}\text { Espesor } \\
(\mathrm{m})\end{array}$ & $\begin{array}{c}\text { Concen } \\
\text { tración } \\
\text { aproximada }\end{array}$ & Clasificación & $\begin{array}{l}\text { Profundidad } \\
\text { calculada por } \\
\text { FLO-2D } \\
\text { (m) }\end{array}$ & $\begin{array}{c}\text { Profundidad } \\
\text { esperada debido a } \\
\text { la concentración } \\
(\mathrm{m})\end{array}$ \\
\hline 03 & 0.45 & 0.5 & FE-FH & $0.80-1.09$ & $0.81-0.99$ \\
\hline 04 & 0.92 & $0.5-0.6$ & FE & $1.28-1.46$ & $1.38-2.02$ \\
\hline 05 & 0.62 & $0.5-0.6$ & $\mathrm{FE}$ & $0.70-0.84$ & $0.93-1.36$ \\
\hline 02 & 0.70 & 0.5 & FE-FH & $1.02-1.16$ & $1.26-1.54$ \\
\hline 06 & 2.00 & 0.5 & FH & 1.36 & $3.60-4.40$ \\
\hline 07 & 0.42 & $0.2-0.5$ & $\mathrm{FE}$ & $0.77-1.05$ & $0.76-2.31$ \\
\hline 09 & 0.86 & $0.5-0.6$ & $\mathrm{FE}$ & 0.60 & $1.29-1.89$ \\
\hline 10 & 1.28 & $0.5-0.6$ & $\mathrm{FE}$ & $0.33-0.77$ & $1.92-2.82$ \\
\hline 11 & 0.47 & 0.5 & FE-FH & $0.18-0.95$ & $0.85-1.03$ \\
\hline 12 & 0.47 & 0.5 & FE-FH & $0.60-0.88$ & $0.85-1.03$ \\
\hline
\end{tabular}

en el caso de eventos antiguos y es de gran importancia al momento de generar escenarios de peligro, no sólo en el Popocatépetl, sino en otros volcanes, donde la mayor parte de los escenarios se infieren a partir del registro geológico.

\section{CONCLUSIONES}

Este trabajo documenta las características del lahar Nexpayantla del 4 de febrero del 2010 y sus transformaciones con la distancia, con base en la integración de datos de precipitación, técnicas de percepción remota y estudios texturales del depósito, por lo que representa el único estudio detallado de un lahar secundario en el volcán Popocatépetl. La ocurrencia del lahar está relacionada a una precipitación de 100 $\mathrm{mm} /$ día ocurrida en temporada seca y su origen se debió a que esta lluvia saturó los materiales piroclásticos en las paredes de la barranca Nexpayantla. Lo anterior produjo varios procesos de remoción en masa superficiales, procesos frecuentes en la barranca (Figuras 6a-6c), cuyo material fue depositado en el cauce y removilizado por el lahar. Las imágenes satelitales permitieron reconocer que el depósito observado en campo representa sólo una fracción del área de inundación, por lo cual la interpretación de la magnitud de un evento únicamente a partir de su depósito, podría implicar subestimar un evento de forma importante, especialmente en lahares con gran porcentaje de troncos de árboles y un bajo contenido de material fino, en donde rápidamente ocurren transformaciones y sedimentación de material, y que terminan como corrientes diluidas cuyo depósito está ausente o es irreconocible en el campo.

Por otro lado, las simulaciones numéricas utilizadas para reproducir el lahar Nexpayantla reprodujeron adecuadamente la longitud del lahar y el área de inundación, sin embargo, el cálculo de las profundidades en diversas zonas de la barranca mostró que, especialmente en la zona distal y zonas de curvatura, la profundidad fue subestimada en más del $50 \%$. Esto puede deberse a la resolución del modelo digital de elevación y a la variabilidad en la concentración de sedimentos, por lo que las ecuaciones utilizadas por el código numérico para reproducir el comportamiento de flujos con altas concentraciones de sedimentos, como son los lahares, no son las más adecuadas para el resolver la profundidad en flujos con concentraciones de sedimentos cerca de la transición hacia una corriente fluvial y con un alto porcentaje de troncos de árboles.
Finalmente, el lahar Nexpayantla del 4 de febrero del 2010 ocurrió en una de las barrancas del volcán menos estudiadas con respecto a estos fenómenos, y el hecho de que en ella no se encuentren instaladas estaciones de meteorológicas y de monitoreo acústico de flujos, incrementa el riesgo para la población de San Pedro Nexapa y de las personas que trabajan diariamente dentro de la barranca.

\section{AGRADECIMIENTOS}

Agradecemos el apoyo del Laboratorio de Sedimentología del Instituto de Geofísica de la Universidad Nacional Autónoma de México, para realizar el análisis textural de las muestras, a la M.C. Sol de Jesús Moreno Roso por su apoyo en la edición de figuras y los comentarios del Dr. Claus Siebe y un revisor anónimo que ayudaron a mejorar este manuscrito. Este trabajo fue apoyado por los proyectos PAPIIT UNAM IA106317 e IN119620.

\section{REFERENCIAS}

AVA (Aster Volcano Archive), 2016, Imágenes satelitales tipo ASTER. Recuperado de <http://ava.jpl.nasa.gov/index.php>, consulta: 26 de enero 2017.

Barclay, J., Alexander, J., Susnik, J., 2007, Rainfall-induced lahars in the Belham Valley Montserrat, West Indies: Journal of the Geological Society, 164, 815-827, doi: 10.1144/0016-76492006-078

Beverage, J.P., Culbertson, J.K., 1964, Hyperconcentrations of suspended sediment: Journal of the hydraulics division, 90(6), 117-128.

Capra, L., Poblete, M.A., Alvarado, R., 2004, The 1997 and 2001 lahars of Popocatépetl volcano (Central México): textural and sedimentological constraints on their origin and hazards: Journal of Volcanology and Geothermal Research, 131, 351-369, doi: 10.1016/S0377-0273(03)00413-X

Capra, L., Borselli, L., Varley, N., Gavilanes-Ruiz, J. C., Norini, G., Sarocchi, D., Caballero, L., Cortes, A., 2010, Rainfall-triggered lahars at Volcán de Colima, Mexico: surface hydro-repellency as initiation process: Journal of Volcanology and Geothermal Research, 189(1-2), 105-117, doi: 10.1016/j. jvolgeores.2009.10.014

Capra, L., Caballero, L., Coviello, V., Ferrés, D., Márquez-Ramirez, V.H., 2018a, Intra-eruptive lahars on an active volcano: a combination of earthquake and rainfall effects (resumen), en EGU General Assembly Conference: Vienna, Austria, European Geosciences Union, Abstracts, 20, p. 11992.

Capra, L., Coviello, V., Borselli, L., Márquez-Ramírez, V.-H., ArámbulaMendoza, R., 2018b, Hydrological control of large hurricane-induced lahars: Evidence from rainfall-runoff modeling, seismic and video monitoring: Natural Hazards and Earth System Sciences, 18(3), 781-794, doi: 10.5194/nhess-18-781-2018

CNA-SMN, (Comisión Nacional del Agua-Servicio Meteorológico Nacional), 2015, Archivos de datos de Normales climatológicas del Servicio Meteorológico Nacional, <http://smn.conagua.gob.mx>.

Coviello, V., Capra, L., Norini, G., Dávila, N., Ferrés, D., Márquez-Ramirez, V.H., Pico, E., 2020 (in review), Earthquake-induced debris flows at Popocatépetl Volcano, Mexico: Earth Surface Dynamics Discussion, https://doi.org/10.5194/esurf-2020-36

Delgado, H., Cassatta, W., Gisbert, G., Renee, P., 2017, 3. Los edificios volcánicos antiguos. Historia geológica y eruptiva del volcán Popocatépetl, en Martin del Pozzo, A.L., Alatorre, M., Arana, L., Bonasia, R., Capra, L., Cassata, W., Córdoba, G., Cortés, J., Delgado, H., Ferrés, D., Fonseca, R., García, J.A., Gisbert, G., Guerrero, D.A., Jaimes, M.C., Macías, J.L., Nieto, J., Nieto, A., Paredes, P.A., Portocarrero, J., Renne, P., Rodríguez, D.M., Salinas, S., Siebe, C., Tellez, E. (eds.), Estudios geológicos y actualización del mapa de peligros del volcán Popocatépetl. Memoria técnica del mapa de peligros del volcán Popocatépetl, Monografías del Instituto de Geofísica No. 22: México, Instituto de Geofísica Universidad Nacional Autónoma de México, 166 pp.

Espinasa-Pereña, R, 2014, Historia de la actividad del Volcán Popocatépetl 17 años de erupciones, México: Ciudad de México, México, Centro Nacional 
de Prevención de Desastres, Subdirección de Riesgos Geológicos, 65 pp.

Espinasa-Pereña, R., 2018, Evaluación del riesgo relativo de los volcanes en México, en Foro Internacional: Los volcanes y su impacto: Arequipa, Perú, Instituto Geológico Minero y Metalúrgico, Libro de resúmenes, 168-173.

Espinasa-Pereña, R., Martín-Del Pozzo, A.L., 2006, Morphostratigraphic evolution of Popocatépetl volcano, México, en Siebe, C., Macías, J.L., Aguirre-Díaz, G.J. (eds.), Neogene-Quaternary continental margin volcanism: A perspective from México: McLean, VA, EE.UU., Geological Society of America Special Paper 402, Penrose Conference Series, 115-137.

Franco, R.O., Castillo, M., Muñoz-Salinas, E., 2016, Using tree-ring analysis to evaluate the intra-eruptive lahar activity in the Nexpayantla Gorge, Popocatépetl Volcano (Central Mexico): Catena 147, 205-215, doi: 10.1016/j.catena.2016.06.045

González, A.E., 2000, Estudios de detalle estratigráfico y sedimentológico del Lahar de San Nicolás en el flanco noreste del volcán Popocatépetl: Ciudad de México, México, Universidad Nacional Autónoma de México, Tesis de Ingeniería, $109 \mathrm{pp}$.

González, A.E., Delgado, H., Urrutia, J., 1997, The San Nicolás Lahar at Popocatépetl Volcano (Mexico): a case study of a glacier-ice-mel trelated debris flow, triggered by a blast at the onset of a plinian eruption, en International Association of Volcanology and Chemistry of the Earth's Interior, General Assembly: Puerto Vallarta, Jalisco, México: EE. UU., International Association of Volcanology and Chemistry of the Earth's Interior, 94.

Lancaster, S.T., Hayes, S.K., Grant, G.E., 2003, Effects of wood on debris flow runout in small mountain watersheds: Water Resources Research, 39(6), 1168, doi: 10.1029/2001WR001227

Lavigne, F., 1998, Les lahars du volcan Merapi, Java central, Indonésie: déclenchement, Budget sédimentaire, dynamique et zonage des risques associés: Clermont-Ferrand, Francia, Université Blaise-Pascal, Tesis Doctoral, $539 \mathrm{pp}$.

Macías J.L., 2005, Geología e historia eruptiva de algunos de los grandes volcanes activos de México: Boletín de la Sociedad Geológica Mexicana, LVII, (3), 379-424, doi: 10.18268/bsgm2005v57n3a6

Manville V., Németh K., Kano K., 2009, Source to sink: a review of three decades of progress in the understanding of volcaniclastic processes, deposits, and hazards: Sedimentary Geology, 220, 136-161, doi: 10.1016/j. sedgeo.2009.04.022

Martin del Pozzo, A.L., Alatorre, M., Arana, L., Bonasia, R., Capra, L., Cassata, W., Córdoba, G., Cortés, J., Delgado, H., Ferrés, D., Fonseca, R., García, J.A., Gisbert, G., Guerrero, D.A., Jaimes, M.C., Macías, J.L., Nieto, J., Nieto, A., Paredes, P.A., Portocarrero, J., Renne, P., Rodríguez, D.M., Salinas, S., Siebe, C., Tellez, E., 2017, Estudios geológicos y actualización del mapa de peligros del volcán Popocatépetl. Memoria técnica del mapa de peligros del volcán Popocatépetl: Monografías del Instituto de Geofísica No. 22: Ciudad de México, México, Instituto de Geofísica Universidad Nacional Autónoma de México, 166 pp.

Muñoz-Salinas, E., Manea, V.C., Palacios, D., Castillo-Rodríguez, M., 2007, Estimation of lahar flow velocity on Popocatépetl volcano (Mexico): Geomorphology, 92, 91-99, doi: 10.1016/j.geomorph.2007.02.011

Muñoz-Salinas, E., Castillo-Rodríguez, M., Manea, V., Manea, M., Palacios, D., 2009, Lahar flow simulations using LAHARZ program: Application for the Popocatépetl volcano, Mexico: Journal of Volcanology and Geothermal Research, 182(1-2), 13-22, doi: 10.1016/j.jvolgeores.2009.01.030

O’Brien, J.S, 2009, FLO-2D Software (versión PRO 2009). Windows: Nutrioso, Arizona,, EE.UU., FLO-2D Software, Inc.

O'Brien, J.S., Julien, P.Y., 1988, Laboratory analysis of mudflow properties: Journal of hydraulic engineering, 114(8), 877-887, doi: 10.1061/ (ASCE)0733-9429(1988)114:8(877)
Palacios, D., Zamorano, J.J., Gómez, A., 2001, The impact of present lahars on the geomorphologic evolution of proglacial gorges: Popocatépetl, Mexico: Geomorphology, 37(1-2), 15-42, doi: 10.1016/S0169-555X(00)00061-1

Phillips, J.V., Tadayon, S., 2006, Selection of Manning's Roughness Coefficient for Natural and Constructed Vegetated and Non-Vegetated Channels, and Vegetation Maintenance Plan Guidelines for Vegetated Channels in Central Arizona: U.S. Geological Survey Scientific Investigations Report 2006-5108, $41 \mathrm{pp}$

Procter, J., Cronin, S. J., Fuller, I.C., Lube, G., Manville, V., 2010, Quantifying the geomorphic impacts of a lake-breakout lahar, Mount Ruapehu, New Zealand: Geology, 38(1), 67-70, doi: 10.1130/G30129.1

Proietti, C., Coltelli, M., Marsella, M., Fujita, E., 2009, A quantitative approach for evaluating lava flow simulation reliability: LavaSIM code applied to the 2001 Etna eruption: Geochemistry, Geophysics, Geosystems, 10(9), Q09003, doi:10.1029/2009GC002426

Ramírez de la O., I., 2005, Comunidades en la zona de influencia del Parque Izta-Popo: buscando una ruta hacia el turismo sustentable: El Periplo sustentable, 10, 59-77. Universidad Autónoma del Estado de México.

Rickenmann, D., 1999, Empirical relationships for Debris Flows: Natural Hazards, 19, 47-77, doi: 10.1023/A:1008064220727

Sarocchi, D., Borselli, L., Macías, J.L., 2005, Construcción de perfiles granulométricos de depósitos piroclásticos por métodos ópticos: Revista Mexicana de Ciencias Geológicas, 22(3), 371-382.

Scott, K.M., 1988, Origins, behavior, and sedimentology of lahars and laharrunout flows in the Toutle-Cowlitz River system: Washington D.C., EE.UU. U.S. Geological Survey Professional Paper 1447-A, 74 pp.

Selby, M., 1985, Earth's Changing Surface: An Introduction to Geomorphology: New York, EE.UU., Oxford University Press, 480 pp.

Sheridan, M.F., Hubbard, B., Bursik, M.I., Abrams, M., Siebe, C., Macías, J.L., Delgado, H., 2001, Gauging short-term volcanic hazards at Popocatépetl: EOS, Transactions American Geophysical Union, 82(16), 185-189, doi: 10.1029/01EO00097

Siebe, C., Macías, J.L., Abrams, M., Obenholzner, J., 1996, La destrucción de Cacaxtla y Cholula: un suceso en la historia eruptiva del Popocatépetl: Ciencias, 41, 36-45.

Smith, G.A., Lowe, D.R., 1991, Lahars: volcano-hydrologic events and deposition in the debris flow hyperconcentrated flow continuum: Sedimentation in Volcanic Settings, SEPM Special Publication 45, 59-70.

Spataro, W., D'Ambrosio, D., Rongo, R.,Trunfio, G.A., 2004, An evolutionary approach for modelling lava flows through cellular automata: Cellular Automata, 725-734, Springer. doi: 10.1007/978-3-540-30479-1_75

Vallance, J.W., Scott, K.M., 1997, The Osceola Mudflow from Mount Rainier: sedimentology and hazard implications of a huge clay-rich debris flow: Geological Society of America Bulletin, 109, p. 143-163, doi: 10.1130/0016-7606(1997)109<0143:TOMFMR>2.3.CO;2

Vázquez, R., Capra, L., Caballero, L., Arámbula-Mendoza, R., Reyes-Dávila, G., 2014, The anatomy of a lahar: Deciphering the 15th September 2012 lahar at Volcan de Colima, Mexico: Journal of Volcanology and Geothermal Research, 272, 126-136, doi:10.1016/j.jvolgeores.2013.11.013

Zanuttigh, B., Lamberti, A., 2007, Instability and surge development in debris flows: Reviews of Geophysics, 45, RG3006, 1-45. doi:10.1029/2005RG000175

Manuscrito recibido: febrero 11, 2020

Manuscrito corregido recibido: mayo 27, 2020

Manuscrito aceptado: mayo 28, 2020 